\title{
Avaliação das características microscópicas presentes nas hiperplasias inflamatórias.
}

\author{
Inflammatory hyperplasia: a microscopy study
}

\author{
Cristiano Macabú Badauy * \\ João Jorge Diniz Barbachan ** \\ Pantelis Varvaki Rados ***
}

\section{RESUMO}

As hiperplasias inflamatórias são lesões comuns na cavidade bucal. Entretanto, a literatura descreve diferentes aspectos microscópicos para esta lesão. $\mathrm{O}$ objetivo do presente estudo foi descrever as características histológicas observadas nas hiperplasias inflamatórias diagnosticadas no laboratório de Patologia Bucal da UFRGS e ainda, sugerir critérios histológicos para o diagnóstico desta patologia. Foram revisados 25 casos com diagnóstico de hiperplasia inflamatória arquivados no laboratório de Patologia Bucal da Universidade Federal do Rio Grande do Sul (UFRGS) entre os meses de janeiro e junho do ano 2001. Concluiu-se que a presença de infiltrado inflamatório crônico, hiperplasia epitelial e a direção uniforme das fibras colágenas foram as características histológicas observadas na maioria das lesões.

\section{PALAVRAS-CHAVE}

\section{Hliperplasia. Boca, Patologia. Diagnóstico bucal}

\section{Introdução}

As hiperplasias inflamatórias são um grupo de lesões caracterizadas como massas submucosas que podem se ulcerar secundariamente quando traumatizadas, mostrando a coloração normal da mucosa ou levemente avermelhadas (REGEZI, SCIUBBA, 1991).

A hiperplasia inflamatória caracteriza-se pela proliferação do tecido epitelial da cavidade bucal por aumento no ritmo de divisão celular com manutenção do padrão morfofuncional do tecido (Pinto et al., 1996). $\mathrm{Na}$ maioria dos casos apresenta-se clinicamente como lesão elevada consistência firme com base séssil ou pediculada (Coutinho, Santos, 1998).

Como principal fator etiológico destacase o uso de prótese total desadaptada, os outros fatores relacionados são: presença de Candida albicans, sensibilidade aos materiais da prótese, fatores sistêmicos e enfermidades sistêmicas (Flores, 1998).

Em levantamento realizado por Coelho, Zucoloto (1998) estas patologias representaram $14,5 \%$ dos casos diagnosticados no laboratório de Patologia Bucal da USP.

Diversos pesquisadores atribuíram diferentes nomes à hiperplasia inflamatória, como épulis fissuratum, fibroma irritativo, hiperplasia fibrosa, hiperplasia fibro-epitelial e hiperplasia por prótese (Cutright, 1974; Bassi et al.1998; Zanetti et al.,1996).

As hiperplasias inflamatórias apresentam alterações nos tecidos epitelial e conjuntivo.

No tecido epitelial as principais alterações descritas são a hiperplasia, hiperparaceratose, acantose e degeneração hidrópica. Embora a frequiência em que são encontradas e a intensidade da sua manifestação variem nos diferentes trabalhos presentes na literatura, dependendo da localização da lesão (Tiecke, 1965; Cutright, 1974; Regezi, Sciubba, 1991; Bassi et al. 1998; Flores, 1998; Coelho, Zucoloto, 1998). critas por Lucas (1976) e Coutinho, Santos (1998), que agregaram a elas a presença de áreas atróficas ocasionalmente observadas no tecido epitelial, variando de acordo com o sítio anatômico.

Para Boraks (1996) o exame histopatológico das hiperplasias inflamatórias sercarcinoma espinocelular, principalmente nas lesões localizadas em fundo de sulco, já que Castro (1997) relatou a presença de displasia em alguns dos 665 casos de Hiperplasia inflamatória por ele estudados do Laboratório de Patologia Bucal da UNESP (Araçatuba) e Coelho, Zucoloto (1998) relataram uma frequiência de $3,8 \%$ de displasia observadas nas mesmas lesões. Entretanto, diversos autores não observaram qualquer associação entre a hiperplasia e carcinoma espinocelular (Tiecke, 1965; Cutright, 1974; Lucas 1976)

Em relação componente conjuntivo da hiperplasia fibrosa, vasos sangüíneos dilatados e infiltrado inflamatório constituído principalmente de linfócitos são as alterações microscópicas que, embora variem em intensidade, são freqüentemente observadas (Tiecke, 1965; Cutright, 1974; Regezi, Sciubba, 1991; Dummond, et al., 1995; Bassi, et al. 1998; Flores, 1998)

Para Lucas (1976) o tecido conjuntivo mostra infiltrado inflamatório dependente da intensidade do fator irritante. A disposição das fibras colágenas pode assumir distribuição em bandas que se continuam com os tecidos normais adjacentes.

Assim como a nomenclatura, as caracte-
Estas mesmas características foram desviria para descartar o desenvolvimento de rísticas histológicas descritas na literatura para esta lesão são muito variadas e o objetivo do presente trabalho é descrevê-las com base nos casos de hiperplasias inflamatórias diagnosticadas no laboratório de Patologia Bucal da Faculdade de Odontologia da UFRGS.

\section{MATERIAL E MÉTODO}

Foram examinados 25 casos de hiperplasia inflamatória encaminhados ao laboratório de Patologia Bucal da Faculdade de 0dontologia da UFRGS entre os meses de janeiro a junho do ano 2001 , obtidos a partir de biópsia total dos seguintes sítios anatômicos : gengiva (5), mucosa jugal (7), fundo de sulco (3), bordo de língua (1), palato duro (1), rebordo alveolar (6) e lábio (2), fixados em formalina neutra tamponada a $10 \%$, emblocados em parafina, cortados e submetidos à técnica de coloração pela hematoxilina/eosina. As lâminas foram examinadas em microscópio binocular marca Meiji ${ }^{\circledR}$ utilizando-se um aumento de 40 vezes para observação das características gerais do tecido e aumento de 100 vezes para observação do infiltrado inflamatório.

Os critérios microscópicas adotados no Laboratório de Patologia Bucal da UFRGS são:

- Hiperplasia epitelial: aumento da espessura deste tecido ocasionado pelo maior número de células em todas as suas camadas, mantendo a estratificação normal do tecido.

- Acantose: aumento da espessura do epitélio ocasionada pelo maior número de células na camada espinhosa, mantendo a estratificação normal do tecido. Manifesta-se histologicamente por cristas epiteliais mais largas.

- Hiperortoceratose: aumento da camada ceratinizada do epitélio, com ceratinização completa da célula e desaparecimento do seu

* Especialista em Odontopediatria (UFES), aluno do mestrado em Patologia Bucal da UFRGS ** Professor do curso de mestrado em Patologia Bucal da UFRGS *** Professor do curso de mestrado em Patologia Bucal da UFRGS 
núcleo.

- Hiperparaceratose: aumento da camada ceratinizada do epitélio, com as células superficiais retendo o núcleo.

- Degeneração hidrópica: presença de células com vacúolo no citoplasma.

- Atrofia epitelial: diminuição da espessura do tecido em relação às áreas de hiperplasia.

- Hiperplasia do tecido conjuntivo: aumento da espessura deste tecido pelo maior número de células e fibras.

- Hiperemia: presença de vasos abertos, num campo microscópico em aumento de 40 vezes.

$\mathrm{Na}$ avaliação do infiltrado foram considerados os seguintes critérios: predomínio de células mononucleares ou polimorfonucleares, distribuição das células (local ou difusa) e a localização preferencial das células inflamatórias conforme estivessem penetrando o epitélio, na camada subepitelial ou profundamente no tecido conjuntivo. As características microscópicas de cada lâmina foram registradas e posteriormente analisadas e comparadas.

\section{RESULTADOS}

Do estudo dos 25 casos observamos que houve aumento da espessura do epitélio ocorrendo em 25 (100\%) casos, presença de degeneração hidrópica em 14 (56\%) casos (tabela 1 e figuras la e 1b), 12 (48\%) casos encontrou-se hiperceratose, sendo que a paraceratinização foi o achado predominante (98 \% dos casos). Apesar do espessamento do tecido epitelial ser uma alteração constante, pode-se observar áreas de atrofia, comparada às áreas de hiperplasia deste tecido em 12 casos (48\%). A acantose foi obsevada em 8 casos (32\%).

$\mathrm{O}$ tecido conjuntivo se mostrou hiperplásico e com feixes de fibras colágenas dispostos numa direção única, quando observados no seu eixo longitudinal em todos os 25 casos (figuras 3a e $3 \mathrm{~b}$ ). 0 infiltrado inflamatório também foi um achado presente nos 25 casos estudados (figuras 1a e 1 b). Considerandose a morfologia das células inflamatórias, os linfócitos e plasmócitos predominaram em 22 casos (88 \%) enquanto os polimorfonucleares prevaleceram nos 3 casos restantes (12\%). 0 infiltrado se apresentou de maneira focal em 17 casos (68\%), com localização na camada subepitelial em 21 espécimes estudados $(84 \%)$.

A presença de capilares abertos foi descrita como hiperemia estando presente em 8 casos (32\%), e pode ser vista nas figuras $2 \mathrm{a}$ e $2 \mathrm{~b}$, enquanto 2 áreas de supuração $(8 \%)$ também estavam presentes ( tabela 2). E importante salientar que as alterações poderiam se superpor numa mesma lâmina ou campo histológico, como pode ser visto nas figuras la e $1 \mathrm{~b}$.

\begin{tabular}{|c|c|c|c|}
\hline \multicolumn{2}{|c|}{$\begin{array}{l}\text { Tabela 1. Alteragốes observadas no tecido } \\
\text { epitelial das hiperplasias inflamatórias. Labo- } \\
\text { ratório de Patologia Bucal da UFRGS } 2001 .\end{array}$} & \multicolumn{2}{|c|}{$\begin{array}{l}\text { Tabela 2. Alterações observadas no tecido } \\
\text { conjuntivo das hipeplasias inflamatórias. La- } \\
\text { boratório de Patologia Bucal da UKRGS } 2001 .\end{array}$} \\
\hline Tipo de alteração & Número de casos & Tipo de alteração & Número de casos \\
\hline $\begin{array}{l}\text { Hiperplasia } \\
\text { Degeneração hidrópica } \\
\text { Áreas de compressão } \\
\text { Hiperceratose } \\
\text { Acantose }\end{array}$ & $\begin{array}{l}25 \\
14 \\
12 \\
12 \\
8\end{array}$ & $\begin{array}{l}\text { Presença de infiltrado } \\
\text { inflamatório } \\
\text { Hiperemia } \\
\text { Áreas de supuração }\end{array}$ & $\begin{array}{c}25 \\
8 \\
2\end{array}$ \\
\hline
\end{tabular}

\begin{tabular}{|lcc|}
\hline Tabela 3. Caracterização do infiltrado inflamatório presente nas lesões estudadas. Laboratório \\
de Patologia Bucal da UFRGS 2001. & Subdivisão & Número de casos \\
\hline Critério estudado & Linfócitos e Plasmócitos & 22 \\
\hline Célula inflamatória predominante & Polimorfonucleares & 3 \\
& Focal & 17 \\
Distribuição das células inflamatórias & Difusa & 8 \\
& Penetrando o epitélio & 0 \\
Localização das células inflamatórias & Camada subepitelial & 21 \\
& Profundamente no tecido conjuntivo & 4 \\
\hline
\end{tabular}

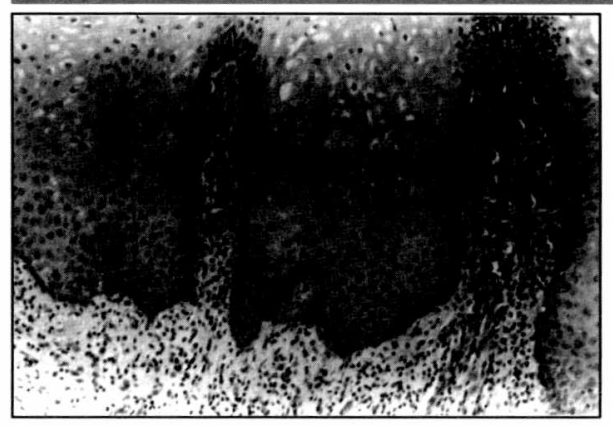

Figura 1a. Fotomicrografia mostrando acantose e degeneração hidrópica do tecido epitelial e infiltrado inflamatório próximo à membrana basal penetrando no tecido epitelial da lesão (HE 100x).

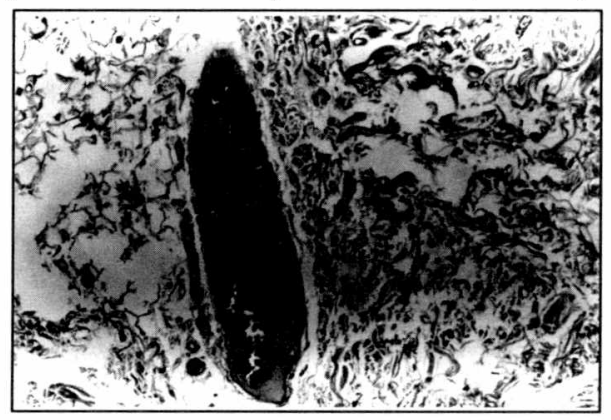

Figura 2a. Fotomicrografia do tecido conjuntivo mostrando um vaso sangüíneo dilatado, que caracteriza a hiperemia tecidual.

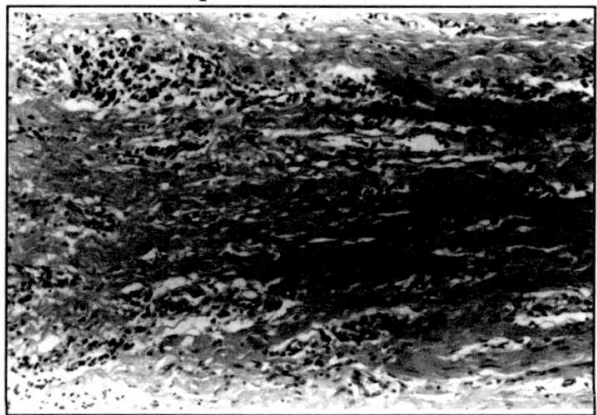

Figura 3a. Fotomicrografia mostrando a disposição uniforme das fibras colágenas no tecido conjuntivo da lesão de hiperplasia inflamatória.

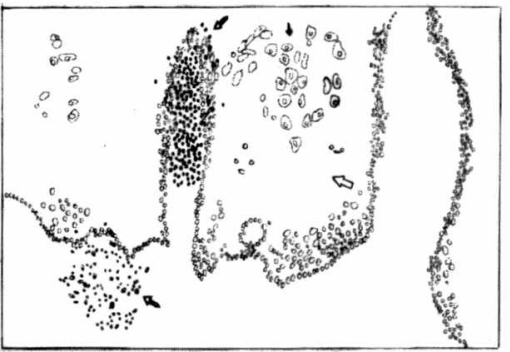

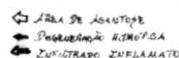

Figura Ib. Esquema ilustrativo da localização da acantose, degeneração hidrópica e distribuição do infiltrado inflamatório visto na figura la.

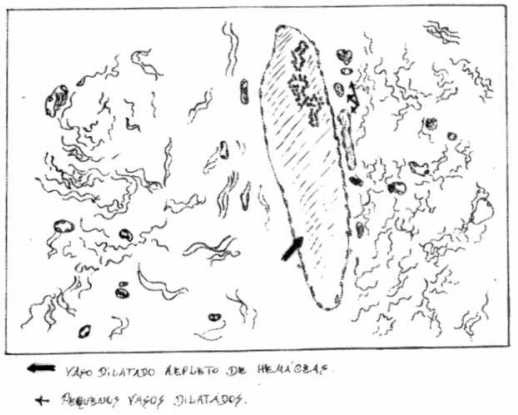

Figura 2b. Esquema ilustrativo de um vaso dilatado e cheio de hemáceas.

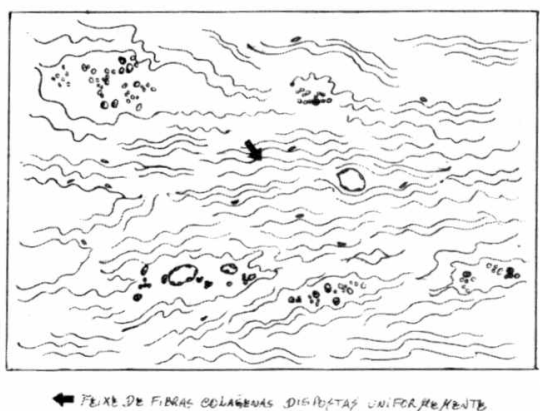

Figura 3b. Esquema ilustrativo da disposição uniforme das fibras colágenas vistas na figura $3 a$. 


\section{DISCUSSÃO}

Apesar das diferentes nomenclaturas atribuídas por diversos autores a esta lesão, acreditamos que o termo hiperplasia inflamatória seja mais adequado por definir a natureza da lesão, isto é, uma resposta tecidual inflamatória frente a uma agressão de baixa intensidade (resposta crônica frente ao trauma).

Considerando-se as características microscópicas em relação à porção epitelial dos 25 casos avaliados pode-se observar que em todos os casos estudados o epitélio se apresentava espessado pelo aumento no número de células em todas as suas camadas, o que seria de se esperar pois é a principal característica da hiperplasia. Outras alterações freqüentemente vistas foram a degeneração hidrópica do epitélio (56 \%), e a hiperparaceratose (48\%). Entretanto estas alterações não são importantes para 0 diagnóstico histopatológico da hiperplasia inflamatória, uma vez que a morfologia do epitélio varia de acordo com o sítio bucal em que este tecido se localiza. No presente estudo 7 das 13 lesões com degeneração hidrópica localizavam-se na mucosa jugal e neste sítio anatômico, o tecido epitelial apresenta freqüentemente, esta alteração. A ocorrência de hiperparaceratose (12 casos) também é explicada pela localização anatômica: 6 lesões observadas no rebordo alveolar, e 6 das 7 lesões observadas na mucosa jugal, onde ocorre morfologicamente um aumento da camada de paraceratina do epitélio. Portanto a presença de degeneração hidrópica e o tipo de ceratinizacão do epitélio não devem ser critérios para o diagnóstico histológico da hiperplasia inflamatória, uma vez que uma mesma lesão pode alternar áreas de epitélio orto e paraceratinizado e áreas normais e com degeneração hidrópica dependendo do sítio anatômico bucal onde se localizava a lesão.

Por outro lado, Coutinho, Santos (1998) relataram a ocorrência de áreas de atrofia epitelial, alternadas com áreas de espessamento deste tecido, que são caracterizadas por encurtamento e achatamento das papilas, fato este também observado em 12 casos deste estudo (48\%). No entanto, podese considerar que sejam áreas de espessura normal do epitélio, que se mostram atróficas quando comparadas às áreas de hiperplasia. Outro fator a ser considerado é a morfologia do epitélio no sítio anatômico da lesão. No presente estudo 3 lesões situavam-se no fundo de sulco (onde o epitélio, morfologicamente tem menor espessura) e as biópsias incluíam tecido da mucosa jugal, dando a falsa impressão de atrofia deste tecido.

Diversos autores relatam associação en- tre hiperplasia inflamatória e carcinoma espinocelular (Boraks' 1996; Castro, 1997; Coelho, Zucoloto 1998). No presente trabalho não observamos qualquer evidência de displasia em nenhum dos 25 casos avaliados e, observando a experiência do Laboratório de Patologia Bucal da UFRGS pode - se afirmar que o carcinoma espinocelular ocorre independentemente da lesão de hiperplasia inflamatória, descartando a possibilidade de o trauma ser um fator etiológico no desenvolvimento desta neoplasia.

0 tecido conjuntivo apresentou-se hiperplásico, $\mathrm{e}$ isto pode ter acontecido pelo aumento do número de células e conseqüente aumento da síntese de fibras colágenas pelos fibroblastos. Este achado está em concordância com as afirmações de TIECKE (1965) que descreveu uma hiperplasia fibrosa no tecido conjuntivo desta lesão, enquanto LUCAS (1976) observou áreas de proliferação fibroblástica. Apesar de GIUNTA (1999) afirmar que o tecido conjuntivo apresenta numerosos feixes de fibras colágenas dispostas de forma irregular nas hiperplasia inflamatórias, no presente estudo a observação do padrão de orientação destas fibras mostrou uma direção quase única, sem o aspecto enovelado presente em outras lesões.

Disperso sobre o estroma fibroso observou-se um infiltrado inflamatório de densidade variável em todos os casos estudados. Esta característica histológica se deve ao fato de ser esta uma lesão que recebe traumatismo crônico, pois está associada na maioria das vezes à prótese total desadaptada (REGEZI SCIUBBA, 1991; BORAKS, 1996), o que leva a uma resposta inflamatória dependente do grau de irritação sobre a lesão (SPOUGE, 1973; LUCAS, 1976; COELHO, ZUCOLOTO, 1999). Além de ativar a resposta inflamatória o trauma favorece a sobreposição de outros agentes como a Candida albicans, o que pode determinar um maior acúmulo de células inflamatórias (REICHART, ALTOFF, 1982). A freqüência do infiltrado inflamatório está relatada em outros estudos da literatura, como os de CUTRIGHT (1974), NEVILLE et al. (1995) e KIGNEL et al. (1999), que consideraram a sua presença freqüente nesta lesão. Sendo uma lesão inflamatória o infiltrado inflamatório deve ser um achado constante, variando apenas na variedade, de acordo com a associação de agentes morbígenos que agem sobre o tecido.

Os linfócitos e plasmócitos predominaram entre as células inflamatórias das lesões estudadas em 22 casos (88\%), apresentando uma distribuição focal em 17 (68\%) e localização preferentemente subepitelial em outros 21 casos (84\%) (tabela 3). Os linfócitos presentes no local da reação produzem mediadores químicos (as linfocinas e fatores de crescimento) que determinam uma reposta proliferativa no tecido conjuntivo. É importante salientar que apesar de o infiltrado assumir um padrão de distribuição preferencial, células inflamatórias podiam ser encontradas em outros pontos da lesão e em 8 (32\%) dos $21(84 \%)$ casos onde o infiltrado se localizava na camada subepitelial observou-se numerosos linfócitos penetrando o epitélio, que poderia ser explicado pela superposição de uma infecção neste tecido, por bactérias ou fungo do gênero Cândida (figura 1a). Em 2 casos (8\%) havia uma resposta mais intensa, com áreas de supuração e em 1 caso (4\%) predomínio dos polimorfonucleares. Consequentemente, o predomínio de infiltrado inflamatório agudo não deve ser interpretado como característica da hiperplasia, mas significa uma provável intensificação do agente agressor sobre a lesão, uma vez que nestes casos, próximo às áreas de acúmulo de polimorfonucleares havia ulceração do tecido epitelial.

Outra característica observada foi a hiperemia, presente em 8 casos $(32 \%)$. Shaffer et al. (1985) justificam o maior número de vasos sanguíneos em razão da reação inflamatória enquanto Saito et al. (1999) relacionaram a patogenia da hiperplasia à presença de fator de crescimento transformante beta, fator de crescimento para fibroblastos e fator de crescimento derivado das plaquetas que são mitogênicos para fibroblastos. Entretanto estas substâncias químicas também são angiogênicas, mas provavelmente não são as responsáveis pela vascularização evidente do tecido conjuntivo da hiperplasia. Em nossa opinião acreditamos que seja a hipermia a principal responsável pelos vasos dilatados, proporcionando maior aporte de células de defesa e substâncias químicas em resposta aos mediadores químicos liberados durante a reação inflamatória, embora algum grau de vascularização ocorra por tratar - se de um tecido de granulação.

\section{CONCLUSÕES}

As características microscópicas observadas com maior freqüência nos casos estudados permitem concluir que:

- As características histológicas vistas em todos os casos de hiperplasia inflamatória foram a hiperplasia epitelial e conjuntiva e a presença de infiltrado inflamatório.

- O infiltrado se mostrou distribuído de forma focal $(68 \%)$ dos casos e localizado na camada subepitelial em $84 \%$ dos casos.

- A direção uniforme das fibras colágenas foi comumentemente observada e é um dos parâmetros para diagnóstico histopatológico da hiperplasia inflamatória.

\section{ABSTRACT}

The inflammatory hyperplasias are lesions extremely common in the oral cavity. 
Nevertheless, in the literature there are different characteristics observed during the histopathologic diagnostic of this lesion. The aim of this study was to describe the microscopic characteristics observed in the inflammatory hyperplasia diagnosticated in the Oral Pathology Lab of the Federal University of Rio Grande do Sul (UFRGS), and recommend histologicals criteria for the diagnostic of this pathology. Twenty-five cases of inflammatory hyperplasia archived in the Oral Pathology Lab of the UFRGS were examinated between january and july of 2001 . We concluded that the presence of cronic inflammatory infiltrated, epitelial hyperplasia and the uniform direction of the collagen fibers were the histological caracteristics finding in the majority of the lesions.

\section{KEYWORDS:}

Hyperplasia. Mouth, Patology. Diagnostic of mouth.

\section{REFERÊNCIAS BIBLIOGRÁFICAS}

AVERY, J.K. Oral Development and Histology. 2nd ed. New York: Thieme Medical Publishes Inc. 1994. p. 302-312.

BASSI, A.P.F.; VIEIRA, E.H.; GABRIELLI, M.A.C. Hiperplasia Fibrosa Inflamatória. RGO, Porto Alegre, v. 46, n. 4, p. 209-211, out./dez. 1998.

BHASKAR, S.N. Patologia Bucal. 4.ed. Rio de Janeiro: Artes Médicas. 1989. 615 p.

BORAKS, S. Diagnóstico Bucal. Rio de Janeiro: Artes Médicas, 1996. 319 p.

CASTRO, A.L. Estomatologia. 2.ed. São Paulo: Santos, 1995. 242 p.

CASTRO, A.L. Hiperplasia Fibrosa Inflamatória de Fórnix do Vestíbulo Bucal: Estudo Clínico e Histológico de 665 casos. 1997. 98 f. Tese (Livre Docência)- Faculdade de Odontologia do Campus de Araçatuba, Universidade Estadual Paulista, Araçatuba.

COELHO, C.M.; ZUCOLOTO, S. Hiperplasia Fibro Epitelial da Cavidade Oral. Rev. Assoc. Paul. Cir. Dent., São Paulo v. 52, n. 5, p. 383-387, set./out. 1998.

COELHO, C.M.; ZUCOLOTO, S. Proliferative Ativity of Denture-Induced Fibrous Inflammatory Hyperplasia Analized by Proliferating Cell Nuclear Antigen Labeling Index. Int. J. Prosthodont., Lombardi, v. 12, no. 1, p. 73-77, Jan./Fev. 1999.
COELHO, C.M.; ZUCOLOTO, S. LOPES, R.A. Denture-Induced Fibrous Inflammatory Hyperplasia: a Retrospective Study in a School of Dentistry. Int. J. Prosthodont., Lombardi, v. 13, no. 2, p. 148-151, Mar./Apr. 2000.

COUTINHO, T.C.L.; SANTOS, M.E.O. Hiperplasia Fibrosa Inflamatória. RGO, Porto Alegre, v. 46, no. 1, p .27-29, jan./mar. 1998.

CUTRIGHT, D.E. The Histopatologic Findings in 583 Cases of Epulis Fissuratum. Oral Surg. Oral Med. Oral Pathol., St. Louis, v. 37, no. 3, p. 401411, Mar. 1974.

DRUMMOND, J.R.; NEWTON, J.P.; YEMM, R. Dental Care of the Elderly. St Louis: Mosby, 1995. 224 p.

FLORES, M.M. Hiperplasia Papilomatosa Inflamatória: Aspectos Clínicos, Histopatológicos y Terapêuticos. Acta Odontol. Venez., Caracas, v. 36, no. 2, p. 34-41, 1998.

GIUNTA, J.L. Gingival Fibrous Nodule. Oral Surg. Oral Med. Oral Path., Oral Rad. End., St Louis, v. 88, no. 4, p. 451-454, Oct. 1999.

KIGNEL, S. et al. Hiperplasia Fibrosa Inflamatória. Rev. Paul. Cir. Dent., São Paulo, v. 21, no. 2, p. 40-44, mar./abr. 1999.

LUCAS, R.B. Pathology of Tumours of the Oral Tissues. 3 ed. Edinburg: Churchil Livingstone, 1976. 426 p.

MIGHELL, A.J.; ROBINSON, P.A.; HUME, W.J. Histochemical and Immunohistochemical Localisation of Elastic System Fibres in Focal Reative Overgrowths of Oral Mucosa. J. Oral Pathol. Med., Copenhagen, v. 26, no. 4, p.153-158, Apr. 1997.

MONTENEGRO, M.R.; FRANCO, M. Patologia Processos Gerais. 3 ed. Rio de Janeiro: Atheneu, 1992. 263 p.

NEVILLE, B.W. et al. Oral and Maxillofacial Pathology. Philadelphia: Saunders, 1995. 711 p.

PETERS, R.; BERCINI, F.; AZAMBUJA, T.W.F. Hiperplasia papilar inflamatória: revisão de literatura e apresentação de caso clínico cirúrgico. Rev. Fac. Odontol. Porto Alegre, Porto Alegre, v. 32, n. 2, p. 7-8, dez. 1996.
PINTO, T.A.S. et al. Estudo da prevalência de arterioesclerose em biópsias de hiperplasia inflamatória da mucosa bucal. Rev. Fac. Odontol. Porto Alegre, Porto Alegre, v. 37, n. 2, p. 11-14, dez. 1996.

RALPH, J.P.; STENHOUSE, D. Dentureinduced hyperplasia of the oral soft tissues. Vestibular lesions, their characteristics and treatment. Brit. Dent. J., London, v. 132, no. 2, Jan. 1972.

REGESI, J.A; SCIUBBA, J.J. Patologia bucal: Correlações clínicopatológicas. Rio de Janeiro: Guanabara Koogan, 1991. $310 \mathrm{p}$.

REICHART, P.A.; ALTHOFF, J. Granular type of denture stomatitis. Oral Surg. Oral Med. Oral Pathol., St Louis, v. 54, no.1, p. 66-72, July 1982.

SAITO, K. et al. Expression of p53 protein and $\mathrm{Ki} 67$ antigen in gingival hyperplasia induced by ninfedipine and phenytoin. J. Periodontol.,Chicago, v. 70, n. 6, p. 581-586, June 1999.

SHAFER, W.G.; HINE, M.K.; LEVY, B.M. Tratado de patologia bucal. 4.ed. Rio de Janeiro: Guanabara Koogan, 1985. 837p.

SPOUGE, J.D. Oral pathology. St Louis: Mosby,1973, 487 p.

TIECKE, R.W. Oral pathology. New York: Mc Graw Hill, 1965. 873 p.

ZANETTI, R.V. et al. Estudo de 60 pacientes portadores de prótese removível: avaliação clínica das lesões nas áreas de suporte da mucosa bucal. RPG, São Paulo, v. 3, n. 3, p. 175-184, jul./set. 1996.

\section{Endereço para contato:}

Rua Ramiro Barcelos no $2492,5^{\circ}$ andar sala 503 (setor de Patologia Bucal da UFRGS) Bairro Santana, Porto Alegre RS. Cep 90035-003.

Telefones: (051) 3316-5023 ; 33165011 (07:30 às 17:30 hs).

E-mail: cristianobodony@ibest.com.br 